\section{Fiber composites as a method of treatment splinting tooth mobility in chronic periodontitis}

\author{
Dewi L. Ichwana*
}

CrossMark

\section{Abstract}

Objective: Patients with periodontal disease can lead to severe tooth mobility, often complains of pain when eating, decreased chewing ability and functional occlusion. Basically, tooth mobility is a symptom of periodontal tissue morphology changes, so it became a challenge for dentists in making decisions to maintain proper care of the teeth. Recent studies aimed to see the use of periodontal splint with Fiber Reinforced Composite (FRC) or fiber composite as a method of treatment splinting tooth mobility.

Methods: A 52-year-old female complaint mandibular teeth rocking since three months ago. Pocket depth of no more than $4 \mathrm{~mm}$, the unsteadiness of degree two on the teeth 41, 31, 32. the non-surgical phase performed oral hygiene instructions, scaling and rootplaning, and splinting with fiber composites for immobilization.

Results: Modulus fiber creates the ability and strength to the fiber to provide promising results against withstand the occlusion and masticatory force.

Conclusion: Treatment of chronic periodontitis patients with splinting fiber composites as a method for stabilization of the lower anterior teeth providing aesthetics, comfort, improved functionality occlusion, mastication and a good prognosis.
Department of Periodontics, Program Study of Dentistry, Faculty of Medicine, University General Achmad Yani Cimahi, Indonesia
*Correspondence to: Dewi Lidya Ichwana, Department of Periodontics, Program Study of Dentistry, Faculty of Medicine, University General Achmad Yani Cimahi, Indonesia dewi.ichwana@lecture.unjani.ac.id

Received: 18 July 2016 Revised: 15 November 2016 Accepted: 22 November 2016 Available Online: 18 December 2016

Keywords: Fiber composites, Periodontitis, Splinting, Tooth mobility.

Cite this Article: Ichwana DL. 2016. Fiber composites as a method of treatment splinting tooth mobility in chronic periodontitis. Journal of Dentomaxillofacial Science 1(3): 190-192. D01:10.15562/jdmfs.v1i3.315

\title{
Introduction
}

Tooth mobility is a common problem on the teeth due to gingiva and bone support disease or injury, furthermore give raise to tooth loss. Tooth mobility may be a physiological or pathological condition. The increased mobility can be caused by many factors. But the inflammation by the accumulation of plaque and trauma due to occlusion were most often factors implicated as the cause of tooth mobility. ${ }^{1-3}$

Splints created to stabilize or tighten mobile tooth due to trauma or periodontal disease. The indications of periodontal splints are tooth mobility which are disruption patient comfort, tooth migration and for the benefit of prosthetic teeth that require many cantilevers. ${ }^{3,4}$

Treatment of periodontal splints used in the state of tooth mobility caused by loss of alveolar bone and disrupt the function of mastication and occlusion. But if there are tooth mobility with the normal conditions of the periodontal ligament and not interfere with the function of mastication or the comfort of the patient, the state does not require a splint. Treatment of cases of tooth mobility must be done well. Proper diagnosis of the factors that cause tooth mobility is needed to achieve success treatment. ${ }^{3,5-7}$

Many materials and restoration techniques have been used in dental splint. Before the dental adhesive restorative material is introduced, the optimal choice for splinting teeth is with a full crown placed on each tooth and united., 8 One advantage of this technique is tooth stabilized with acrylic provisional restoration during treatment periodontal, but the main drawback of this treatment is that all the teeth are covered in a splint should be prepared and reduced in size to the restoration of the crown. In the other way is using the conservative material in order to carry out the treatment in a single visit such as using of wire twisted around the teeth and then covered with resin, or with metal or nylon embedded resin but the clinical failure of this material are easily broken due to mastication force during normal function and parafunction. ${ }^{10,11}$ To encounter these problems, dentists will often placed more resin as a reinforcing material, caused over contouring which leads into food and plaque retention areas and difficult to clean.

In order to change the earlier materials splints, strength materials without interrupting the oral hygiene and can be done in one visit, periodontal splints material form developed of a ribbon-fiber which can be reinforced with a composite resin to create a thin splint but has the strength to the crown splints and may be done in one visit. Fiber glass and polyethylene fiber have been introduced 
for this purpose. Fiber glass is treated with a silane as a bond to the resin, while the polyethylene fibers treated using plasma to improve its chemical bondability. ${ }^{12}$

Many studies show that the fiber reinforcement with composite restorative materials increase flexural strength and modulus. ${ }^{13,14}$

\section{Case Report}

52-year-old female came to the premises of the Hospital ubuntu periodonsia department complaint mandibular teeth rocking since three

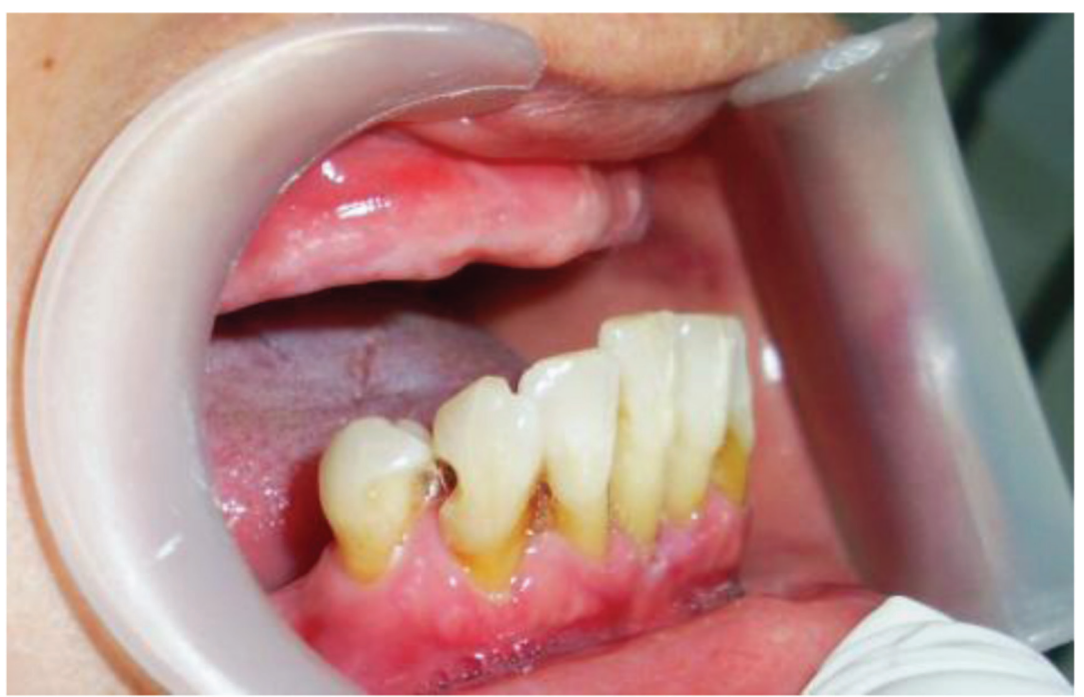

Figure 1 The state of intra oral mandibular anterior teeth on the facial and lingual

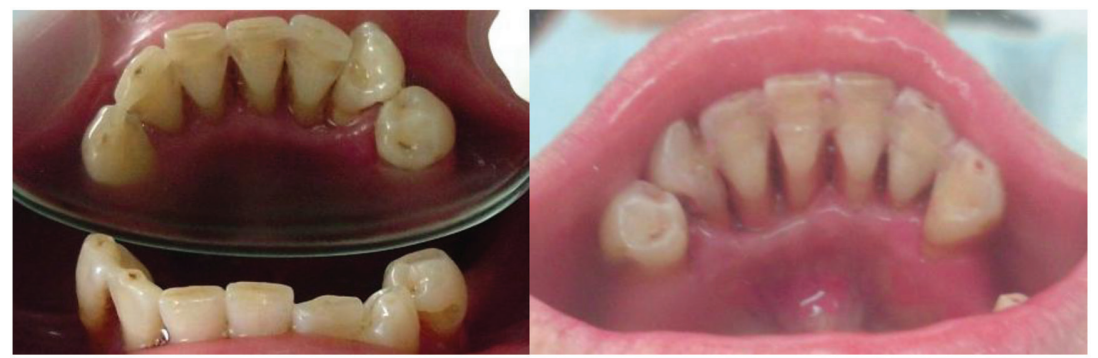

Figure 2 Section lingual prepared, in etching and then in rebonding, then applied fiber

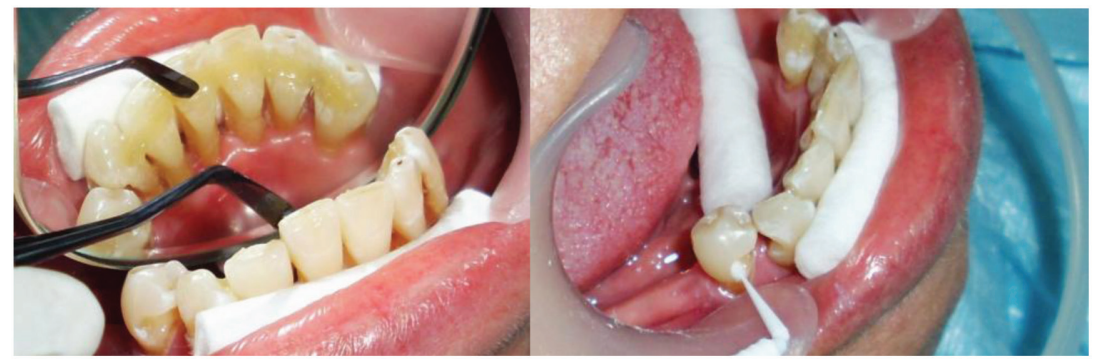

Figure 3 Once the fiber is adapted to the groove, covered with composite resin, the teeth 43 and 44 are prepared for fiber months ago, it hurts when used for chewing or biting, thereby disrupting the comfort. Besides easy bleeding gums and tooth surface feels rough. Extra-oral examination results there is no abnormality and the intra-oral examination found gingival inflammation state, followed by a recession in almost all regions, pocket depth of no more than $4 \mathrm{~mm}$, the unsteadiness of degree two on the teeth $41,31,32$ and oral hygiene was. So the diagnosis is set to a generalized chronic periodontitis with a good prognosis figure 1.

As an initial treatment plan, the non-surgical phase performed oral hygiene instructions, scaling and rootplaning, and splinting with fiber composites for immobilization gear with two degrees of mobility for visits do not require surgical periodontal treatment.

\section{Procedure Fiber Reinforced Composite}

After scaling and rootplaning, diamond bur is used to prepare the grooves on the tooth to be in a splint. Special attention must be taken to avoid injury to the pulp. The area to lay fiber splint that has been prepared, rinsed and dried carefully. Strip fiber prepared, cut with sharp scissors or scalpel and strongly supported by the appropriate finger length of groove teeth will be in a splint that has been measured previously with dental floss. Advantages of fiber used in this technique is able to bind chemically with composite resin.

After the grooves on the tooth that has been prepared in etch, rinsed and dried, bonding is applied in the area. Figure 2 Before bonding polymerised fiber strip placed to the groove, and polymerized. Then the composite resin was applied with due regard to the anatomical shape and thickness of the composite, then cured. Figure $3 \& 4$ Installation of fiber composite finished, splint and occlusion are checked with articulation paper and polished. Figure 5 For the posterior dental splint case, separated fiber applications, should be placed on the occlusal, but also could be placed at the labial surfaces as in this case which is involved by disto-labial caries 43.

\section{Discussion}

Tooth mobility has been described as an important clinical parameters in predicting prognosis. ${ }^{15,16}$ For those reasons and comfort of patients, splinting has been a therapy that is recommended to stabilize the tooth. Formerly stabilization splint straight and teeth using adhesive technique requires wires, pins, or nylon. These materials are only capable of mechanically bonded with resin restorations. Therefore splints with these materials 


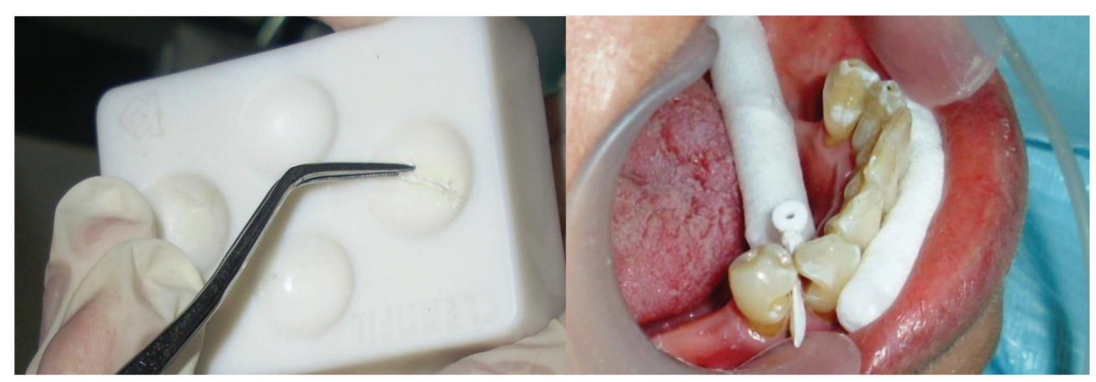

Figure 4 Fiber cut according to size, 43-44 interdental given wedge

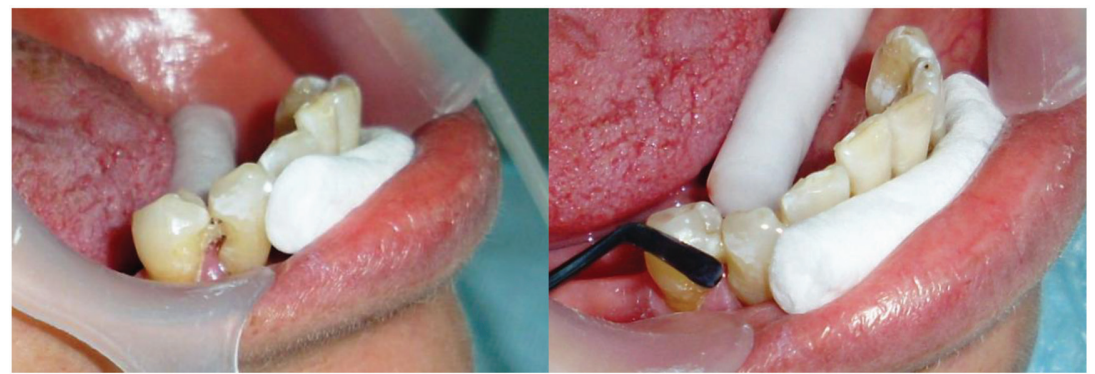

Figure 5 Fiber applied after etching and rebonding, then covered with a composite resin

and potentially cause a shift in stress concentration which will result in the fracture of composite and treatment failure. Splints failure will lead to clinical problems such as traumatic occlusion, periodontal disease progression, and caries. ${ }^{17}$ The introduction of materials that can bind to the bonding agent, such as woven polyethylene fiber, may be resolved the problems. ${ }^{18}$ Rochette reported the fracture strength was significantly higher with materials Ribbond ${ }^{\oplus}$ fiber splints that were restored with ProvipontTM DCH, ie temporary restorative material similar to acrylic resin, and when there is a gap on the restorative material in ProvipontTM DC, it does not propagate beyond polyethylene fiber and splint fixed. ${ }^{18}$ Miller have described the phenomenon increase in fatigue to fracture of short fiber splints in the damaged area. This area absorb energy and control fatigue to fracture and spread of cracks. It explained the fracture toughness of fiber composites. ${ }^{11}$

The evaluation of the restorative material fiber splints as stabilization of teeth on the physical properties and clinical success demonstrated that all of the fiber increase flexural strength and flexural modulus composite resin increases. All splints using these materials show the clinical success after one year. ${ }^{19,20}$ Other study also explained the same thing by using fiber splints ribbond ${ }^{\oplus}$ reinforcement ribbon at 42-84 months of study, splints fiber composite gave the excellence result. ${ }^{10}$

\section{Conclusion}

The case report describes an innovative technique use thin materials and bondable fiber splint with composite resin restorations. This fracture-resistant restorations will be more durable than most alternatives splint material in the past.

\section{References}

1. Tarnow DP, Fletcher P. Splinting of periodontally involved teeth: indications and contraindications. NY State Dent J 1986;52: 24-25.

2. Serio FG, Hawley CE. Periodontal trauma and mobility. Diagnosis and treatment planning. Dent Clin North Am 1999;43: 37-44.

3. Waerhaug J. Justification for splinting in periodontal therapy. J Prosthet Dent 1969;22: 201-208.

4. Bhaskar SW, Orban B. Experimental occlusal trauma. J Periodontol 1955;26: 270-284.

5. Ramfjord SP, Kohler CA. Periodontal reaction to functional occlusal stress. J Periodontol 1959;30: 95-112.

6. Kegel W, Selipsky H, Phillips C. The effect of splinting on tooth mobility. I. During initial therapy. J Clin Periodontol 1979;6: 45-58.

7. Galler C, Selipsky H, Phillips C, et al. The effect of splinting on tooth mobil- ity. (2) After osseous surgery. J Clin Periodontol 1979;6: 317-333.

8. Amsterdam M. Periodontal prosthesis. Twenty-five years in retrospect. Alpha Omegan 1974;67: 8-52.

9. Siegel SC, Driscoll CF, Feldman S. Tooth stabilization and splinting before and after periodontal therapy with fixed partial dentures.

10. Pollack RP. Non-crown and bridge stabilization of severely mobile, periodontally involved teeth. A 25-year perspective. Dent

11. Miller TE. A new material for periodontal splinting and orthodontic retention. Compend Contin Educ Dent 1993;14: 800-812.

12. Siegel SC, Driscoll CF, Feldman S. Tooth stabilization and splinting before and after periodontal therapy with fixed partial dentures. Dent Clin North Am 1999;43: 45-76.

13. Christensen G. Reinforcement fibers for splinting teeth. CRA Newsletter 1997;21: 1-2.

14. Strassler HE, Karbhari V, Rudo D. Effect of fiber reinforcement on flexural strength of composite. J Dent Res 2001;80: 221.

15. McGuire MK, Nunn ME. Prognosis versus actual outcome. II. The effectiveness of clinical parameters in developing an accurate prognosis. J Periodontol 1996;67: 658-665.

16. Bernal G, Carvajal JC, Munoz-Viveros CA. A review of the clinical manage- ment of mobile teeth. J Contemp Dent Pract 2002;3: 10-22.

17. Strassler HE, Serio FG. Stabilization of the natural dentition in periodontal cases using adhesive restorative materials. Periodontal Insights 1997;4: 4-10.

18. Rochette AL. Attachment of a splint to enamel of lower anterior teeth. J Prosthet Dent 1973;30: 418-423.

19. Liatukas EL. An amalgam and composite resin splint for posterior teeth. J Prosthet Dent 1973;30: 173-175.

20. Fusayama T. Permanent splint of highly mobile teeth. J Prosthet Dent 1973;30: 53-55.

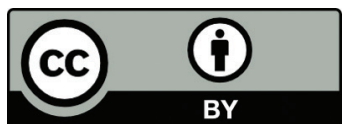

This work is licensed under a Creative Commons Attribution 